\title{
Disinfection of SARS-CoV-2 Contaminated Surfaces of Personal Items with UVC-LED Disinfection Boxes
}

\author{
Maren Bormann ${ }^{1}$ (D), Mira Alt ${ }^{1}$, Leonie Schipper ${ }^{1}$, Lukas van de Sand ${ }^{1} \mathbb{D}$, Mona Otte ${ }^{1}$, Toni Luise Meister ${ }^{2} \mathbb{D}$, \\ Ulf Dittmer $^{3}$, Oliver Witzke ${ }^{1}$, Eike Steinmann ${ }^{2}$ and Adalbert Krawczyk 1,3,*
}

1 West German Centre of Infectious Diseases, Department of Infectious Diseases, Universitätsmedizin Essen, University Duisburg-Essen, 45147 Essen, Germany; Maren.Bormann@uk-essen.de (M.B.);

Mira.Alt@uk-essen.de (M.A.); Leonie.Schipper@uk-essen.de (L.S.); Lukas.vandeSand@uk-essen.de (L.v.d.S.); Mona.Otte@uk-essen.de (M.O.); Oliver.Witzke@uk-essen.de (O.W.)

2 Department of Molecular and Medical Virology, Faculty of Medicine, Ruhr University Bochum, 44801 Bochum, Germany; toni.meister@rub.de (T.L.M.); eike.steinmann@rub.de (E.S.)

3 Institute for Virology, University Hospital Essen, University Duisburg-Essen, 45147 Essen, Germany; Ulf.Dittmer@uk-essen.de

* Correspondence: adalbert.krawczyk@uni-due.de

check for

updates

Citation: Bormann, M.; Alt, M.; Schipper, L.; van de Sand, L.; Otte, M.; Meister, T.L.; Dittmer, U.; Witzke, O.;

Steinmann, E.; Krawczyk, A.

Disinfection of SARS-CoV-2

Contaminated Surfaces of Personal

Items with UVC-LED Disinfection

Boxes. Viruses 2021, 13, 598. https://

doi.org/10.3390/v13040598

Academic Editor: Anne Goffard

Received: 4 March 2021

Accepted: 29 March 2021

Published: 31 March 2021

Publisher's Note: MDPI stays neutral with regard to jurisdictional claims in published maps and institutional affiliations.

Copyright: (C) 2021 by the authors. Licensee MDPI, Basel, Switzerland. This article is an open access article distributed under the terms and conditions of the Creative Commons Attribution (CC BY) license (https:// creativecommons.org/licenses/by/ $4.0 /)$.

\begin{abstract}
The severe acute respiratory syndrome coronavirus 2 (SARS-CoV-2) is transmitted from person to person by close contact, small aerosol respiratory droplets, and potentially via contact with contaminated surfaces. Herein, we investigated the effectiveness of commercial UVC-LED disinfection boxes in inactivating SARS-CoV-2-contaminated surfaces of personal items. We contaminated glass, metal, and plastic samples representing the surfaces of personal items such as smartphones, coins, or credit cards with SARS-CoV-2 formulated in an organic matrix mimicking human respiratory secretions. For disinfection, the samples were placed at different distances from UVC emitting LEDs inside commercial UVC-LED disinfection boxes and irradiated for different time periods (up to $10 \mathrm{~min}$ ). High viral loads of SARS-CoV-2 were effectively inactivated on all surfaces after 3 min of irradiation. Even $10 \mathrm{~s}$ of UVC-exposure strongly reduced viral loads. Thus, UVC-LED boxes proved to be an effective method for disinfecting SARS-CoV-2-contaminated surfaces that are typically found on personal items.
\end{abstract}

Keywords: SARS-CoV-2; UVC-box; ultraviolet light

\section{Introduction}

Since the end of 2019, a novel coronavirus called the severe acute respiratory syndrome coronavirus 2 (SARS-CoV-2) has been spreading worldwide, thereby causing a major public health issue [1]. Coronavirus disease 2019 (COVID-19) is caused by SARS-CoV-2 and characterized by symptoms ranging from mild respiratory illness to severe life-threatening pneumonia and acute respiratory distress syndrome (ARDS) [2]. Reducing the transmission of the virus by suitable preventive measures is highly important for controlling the pandemic. SARS-CoV-2 is transmitted by direct contact with infected individuals, by viruscontaining aerosols and potentially via virus-contaminated surfaces [3]. Recent studies have shown that SARS-CoV-2 can persist on smooth surfaces such as glass, metal, and plastic for up to seven days at room temperature, remaining a potential risk of infection [4].

UV-irradiation is an environmentally friendly method to disinfect surfaces from bacteria, fungi, and viruses such as SARS-CoV-2 [5,6]. Under laboratory conditions, high viral loads of SARS-CoV-2 in cell culture medium could be completely inactivated by UVC-irradiation after 9 min of irradiation with a UVC dose of $1048 \mathrm{~mJ} / \mathrm{cm}^{2}$ [7]. For private use, commercial UVC-LED boxes are available for the disinfection of personal items such as smartphones, keys, coins, or credit cards. However, the performance of such devices on the inactivation of SARS-CoV-2 on surfaces has not yet been investigated. Therefore, in the present study, we investigated the ability of two UVC-LED boxes to disinfect surfaces such 
as glass, metal, and plastics typically found on personal items from contamination with high viral loads of SARS-CoV-2.

\section{Materials and Methods}

\subsection{Cells and Viruses}

Vero E6 cells (American Type Culture Collection, ATCC, CRL-1586, Rockville, MD, USA) were cultured in Dulbecco's Modified Eagle's Medium (DMEM) supplemented with $10 \%(v / v)$ fetal calf serum (FCS), penicillin $(100 \mathrm{IU} / \mathrm{mL})$, and streptomycin $(100 \mu \mathrm{g} / \mathrm{mL})$ (all Life Technologies Gibco, Darmstadt, Germany). SARS-CoV-2 was isolated from a nasopharyngeal swab of a patient hospitalized due to COVID-19 at the Department of Infectious Diseases of the University Hospital Essen in April 2020 [7]. In brief, the virus was propagated on Vero E6 cells cultured in DMEM supplemented with $10 \%(v / v)$ FCS, penicillin $(100 \mathrm{IU} / \mathrm{mL})$, streptomycin $(100 \mu \mathrm{g} / \mathrm{mL})$, and ciprofloxacin $(10 \mu \mathrm{g} / \mathrm{mL})$. After 5 days of incubation, virus suspension was harvested, cleared from cell debris by centrifugation, and stored at $-80^{\circ}$. Viral titers were determined by endpoint dilution according to Spearman and Kärber [8] and calculated as TCID $_{50}$ (tissue culture infectious dose, 50\%).

\subsection{Measurement of the Emitted Light Intensity}

Two UVC-LED boxes were investigated for their capability to inactivate SARS-CoV-2 (UVC-LED box 1, Horcol; UVC-LED box 2, expondo GmbH, Berlin, Germany). A radiometrically calibrated spectrometer (STS-UV-L-50-400-SMA, Ocean Optics B.V., Ostfildern, Germany) with a sensitivity range between 190 and $650 \mathrm{~nm}$ (1.5 nm resolution) equipped with a CC-3-UV-S corrector (Ocean Optics B.V., Ostfildern, Germany) was used to determine the light intensity emitted by the LEDs inside the UVC-LED boxes. The emitted light intensity was determined between a wavelength of 250 and $280 \mathrm{~nm}$ at specific distances from the light source (LED) of the UVC-LED boxes. The corrector was placed at the same locations as the virus carriers (UVC-LED box 1: 1 and $5 \mathrm{~cm}$ horizontal distance; UVC-LED box 2: $1 \mathrm{~cm}$ vertical distance). For UVC-LED box 2, emitted light could only be measured at a distance of $1 \mathrm{~cm}$. A measurement at $4 \mathrm{~cm}$ distance would have required drilling a hole into the bottom of the box, which was not possible without damaging the box. The data were recorded using OceanView 2.0 Software and visualized using GraphPad Prism 9 (GraphPad Software, San Diego, CA, USA).

\subsection{UVC-LED Decontamination of SARS-CoV-2 Contaminated Surfaces}

SARS-CoV-2 working stocks $\left(5 \times 10^{6} \mathrm{TCID}_{50} / \mathrm{mL}\right.$ for UVC-LED box $1 ; 2 \times 10^{6} \mathrm{TCID}_{50} / \mathrm{mL}$ for UVC-LED box 2) were diluted in a defined organic matrix mimicking respiratory secretions [9]. In brief, $900 \mu \mathrm{L}$ of the respective virus stock was added to $100 \mu \mathrm{L}$ organic matrix consisting of $2.5 \mathrm{mg} / \mathrm{mL}$ mucin type I-S, $7.8 \mathrm{mg} / \mathrm{mL}$ BSA Fraction $\mathrm{V}$, and $11 \mathrm{mg} / \mathrm{mL}$ yeast extract (all Sigma-Aldrich, Darmstadt, Germany). We used glass (cover glass, $1.8 \times$ $1.8 \mathrm{~cm}$, Carl Roth, Karlsruhe, Germany), metal (stainless steel, diameter of about $2 \mathrm{~cm}$ ), and plastic (polyvinylchloride, diameter of about $2 \mathrm{~cm}$ ) carriers for viral contamination. Before inoculating the virus suspension to the carriers, the carriers were sterilized for 10 min with a UV-lamp emitting $1940 \mu \mathrm{W} / \mathrm{cm}^{2}$ UVC at $254 \mathrm{~nm}$ (UV-4 S/L, Herolab, Wiesloch, Germany) [7]. After sterilizing, $50 \mu \mathrm{L}$ of the respective virus suspension were placed on the center of the carriers and allowed to dry for $1 \mathrm{~h}$ at room temperature. The carriers were positioned at different distances from the UVC-LEDs inside the UVC-LED boxes (UVCLED box 1: 1 and $5 \mathrm{~cm}$ horizontal distance; UVC-LED box 2: 1 and $4 \mathrm{~cm}$ vertical distance). The carriers were irradiated for specific durations ( $0 \mathrm{~s}, 10 \mathrm{~s}, 30 \mathrm{~s}, 1 \mathrm{~min}, 3 \mathrm{~min}$, and $10 \mathrm{~min})$. Subsequently, the infectious virus was recovered by vortexing the carriers placed in plastic containers (SARSTEDT, Nümbrecht, Germany) filled with $2 \mathrm{~mL}$ DMEM for $1 \mathrm{~min}$. As control, the virus was recovered $10 \mathrm{~min}$ after drying without irradiation. The experiments were conducted in triplicates, and the viral loads were determined by endpoint dilution according to Spearman and Kärber. The limit of detection of the assay was at 159 TCID $50 / \mathrm{mL}$. The means, standard deviations of the viral titers, and $90 \%$ effective concentration (EC 90 ) 
values were calculated with GraphPad Prism 9 (GraphPad Software, San Diego, CA, USA). The statistical significances were determined with the t-test. Comparisons were considered significant at ${ }^{*}<0.05 ;{ }^{* *} p<0.01 ;{ }^{* *} p<0.001$; and ${ }^{* * *} p<0.0001$.

\section{Results}

SARS-CoV-2 can potentially be transmitted via virus-contaminated surfaces of personal items such as smartphones, keys, coins, or credit cards that have been contaminated with the virus. We investigated the performance of two commercially available UVC-LED boxes for virus inactivation on surfaces typically found on personal belongings such as glass, metal, and plastic. We used two different UVC-LED boxes for sterilizing, one with lateral UVC-LEDs (Figure 1A) and one with UVC-LEDs incorporated in the lid of the box (Figure 1B). Additionally, a mirror was installed to the bottom of the chamber. For UVCLED box 1, the emitted light intensity was determined with $245 \mu \mathrm{W} / \mathrm{cm}^{2}$ at horizontal distance of $1 \mathrm{~cm}$ and $65 \mu \mathrm{W} / \mathrm{cm}^{2}$ in the center of the box at horizontal distance of $5 \mathrm{~cm}$ from the UVC-LEDs (corresponding to 0.245 and $0.065 \mathrm{~mJ} / \mathrm{cm}^{2}$ per second, respectively; Figure 2A). For both distances, the peak wavelength emission was measured at around $254 \mathrm{~nm}$. For UVC-LED box 2, the emitted light intensity was measured with $117 \mu \mathrm{W} / \mathrm{cm}^{2}$ at $1 \mathrm{~cm}$ vertical distance from the LEDs, which corresponds to $0.117 \mathrm{~mJ} / \mathrm{cm}^{2}$ per second (Figure 2B). The peak wavelength emission was detected at $280 \mathrm{~nm}$.

a

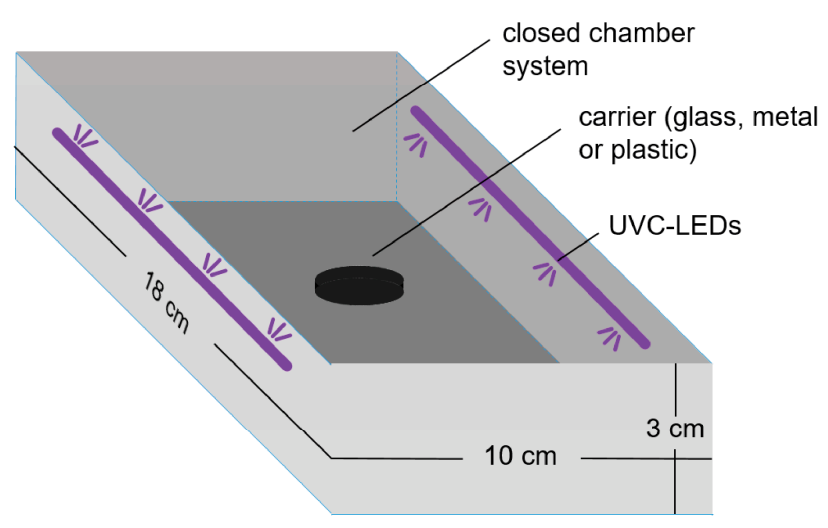

b

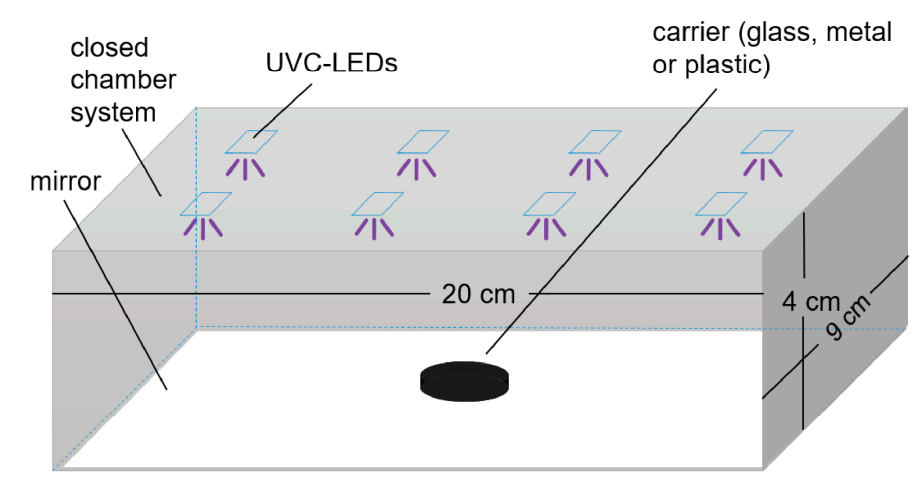

Figure 1. Schematic illustrations of the UVC-LED boxes used for UVC-disinfection. (a) UVC-LED box 1 (Horcol) was equipped with lateral UVC-LEDs. (b) UV-LED box 2 (expondo GmbH, Berlin, Germany) was equipped with UVC-LEDs incorporated in the lid and a mirror installed at the bottom of the chamber.

Next, metal, glass, or plastic samples were overlaid with SARS-CoV-2. The SARS-CoV2 stocks were diluted with an organic matrix mimicking respiratory secretions, resulting in a final virus concentration of the samples of $4.5 \times 10^{6} \mathrm{TCID}_{50} / \mathrm{mL}$ for the experiments in UVC-LED box 1 and $1.8 \times 10^{6} \mathrm{TCID}_{50} / \mathrm{mL}$ for the experiments in UVC-LED box 2, respectively. Compared to the viral load immediately after drying, there was no significant reduction of the viral loads after $10 \mathrm{~min}$ without irradiation (Figure 3). 


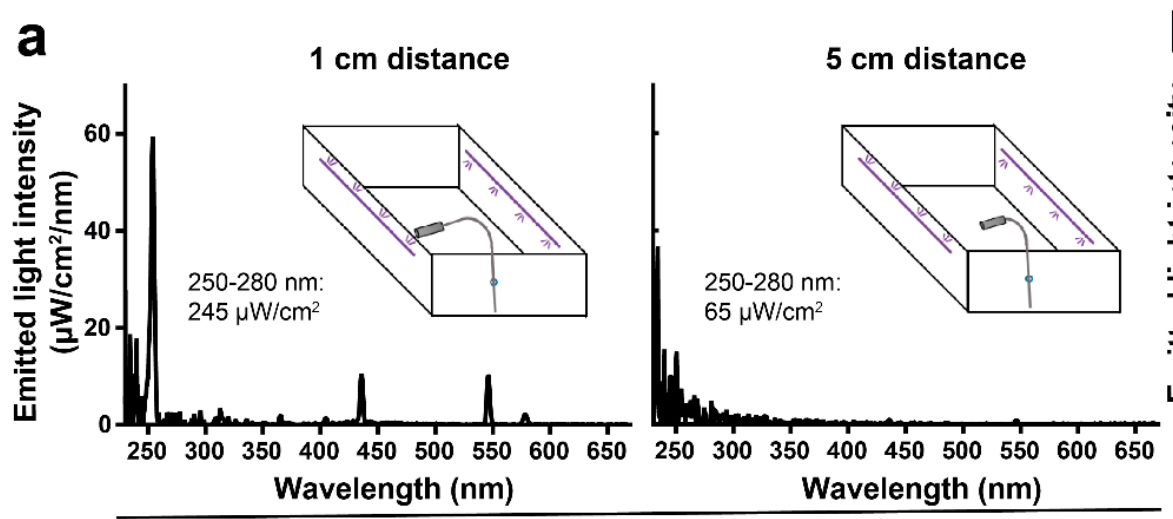

UVC-LED box 1

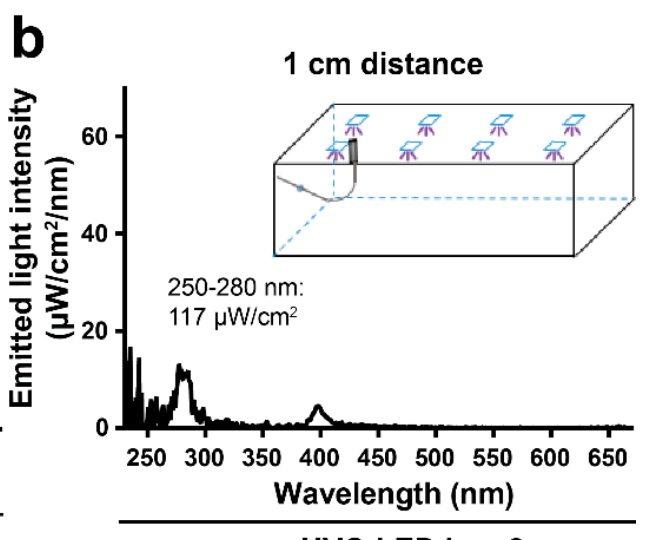

UVC-LED box 2

Figure 2. Spectrum of the emitted light intensity by LEDs inside of the UVC-LED boxes. The emitted light energy was measured by using a radiometrically calibrated spectrometer (STS-UV-L-50-400-SMA, Ocean Optics B.V., Ostfildern, Germany) with a sensitivity range between 190 and $650 \mathrm{~nm}$ (1.5 nm resolution) equipped with a CC-3-UV-S corrector (Ocean Optics B.V., Ostfildern, Germany). (a) The spectrum of emitted light intensity of UVC-LED box 1 was measured at 1 and $5 \mathrm{~cm}$ horizontal distance from the lateral UVC-LEDs. (b) The spectrum of emitted light intensity of UVC-LED box 2 was measured at $1 \mathrm{~cm}$ vertical distance from the UVC-LEDs. Emitted light intensity $\left(\mu \mathrm{W} / \mathrm{cm}^{2}\right)$ between 250 and $280 \mathrm{~nm}$ is displayed for each spectrum. Schematic illustrations indicate the borehole and the UVC-detector placed inside of the box for the respective measurement.

UVC-LED irradiation conducted with UVC-LED boxes proved to be an appropriate method for the disinfection of SARS-CoV-2-contaminated surfaces. SARS-CoV-2-contaminated glass, metal, or plastic samples were effectively UVC-disinfected inside of both UVC-LED boxes (Figure 3). A significant reduction of viral loads of SARS-CoV-2 on glass, metal, and plastic was achieved even after $10 \mathrm{~s}$ of irradiation (UVC-LED box $1: 2.45 \mathrm{~mJ} / \mathrm{cm}^{2}$; UVC-LED box 2: $1.17 \mathrm{~mJ} / \mathrm{cm}^{2}$ ) at a distance of $1 \mathrm{~cm}$ from the LEDs in both UVC-LED boxes (Figure 3). When using UVC-LED box 1, no virus was detectable after 3 (glass and plastic) or $10 \mathrm{~min}$ (metal) of irradiation at a distance of $1 \mathrm{~cm}$ (Figure 3A). At a distance of $5 \mathrm{~cm}$ from the LEDs (UVC-LED box 1), viral loads were strongly reduced after 3 and 10 min of irradiation (3 min: glass: $88.27 \pm 1.49 \%\left(0.93 \pm 0.05 \log _{10}\right)$, metal: $88.26 \pm 3.32 \%\left(0.93 \pm 0.09 \log _{10}\right)$, plastic: $90 \pm 1.38 \%\left(1 \pm 0.05 \log _{10}\right) ; 10$ min: glass: $91.92 \pm 1.85 \%\left(1.1 \pm 0.08 \log _{10}\right)$, metal: $98.52 \pm 0.42 \%\left(1.83 \pm 0.09 \log _{10}\right)$, plastic: $92.56 \pm 1.7 \%\left(1.13 \pm 0.8 \log _{10}\right)$; Figure $\left.3 \mathrm{~A}\right)$. When using UVC-LED box 2, SARS-CoV-2 was almost completely inactivated after 3 and $10 \mathrm{~min}$ of irradiation at a distance of $1 \mathrm{~cm}(3 \mathrm{~min}$ : glass: $97.49 \pm 0.35 \%(1.6 \pm 0.05 \log 10)$, metal: $99.21 \pm 0.1 \%\left(2.1 \pm 0.05 \log _{10}\right)$, plastic: $98.74 \pm 0.16 \%\left(1.9 \pm 0.05 \log _{10}\right) ; 10 \mathrm{~min}:$ glass: $97.85 \pm 0.27 \%\left(1.67 \pm 0.05 \log _{10}\right)$, metal: $99.42 \pm 0.08 \%\left(2.23 \pm 0.05 \log _{10}\right)$, plastic: $99.46 \%$ (2.27 $\log _{10}$ ); Figure 3B). At a distance of $4 \mathrm{~cm}$, no SARS-CoV-2 was detectable on glass, metal, and plastic after 10 min of irradiation (Figure 3B).

Taken together, our data demonstrate that UVC-LED sterilization boxes can effectively inactivate SARS-CoV-2 on surfaces such as glass, metal, or plastic. 
a

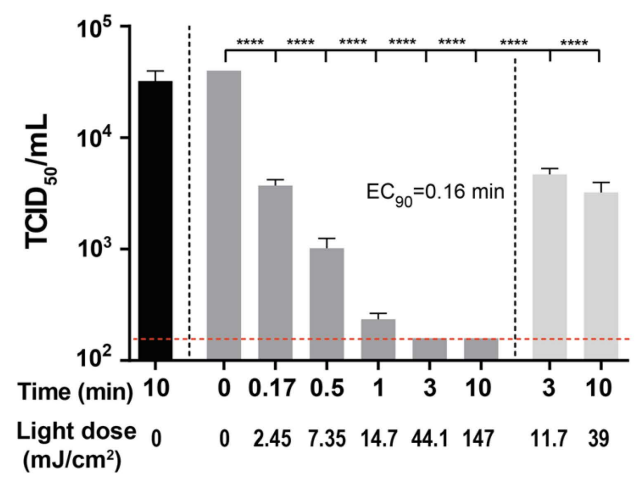

b

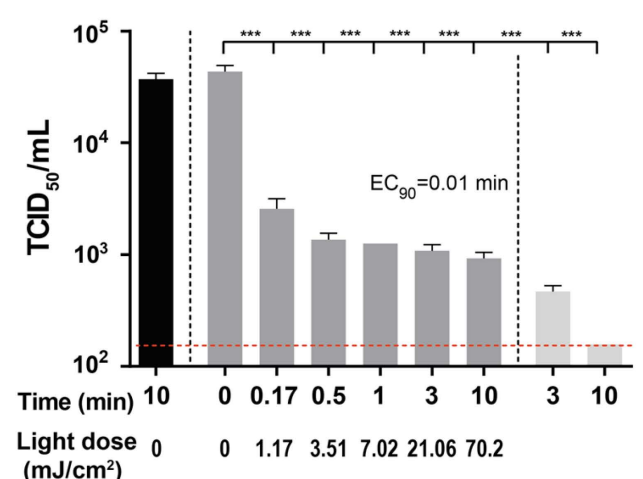

Metal

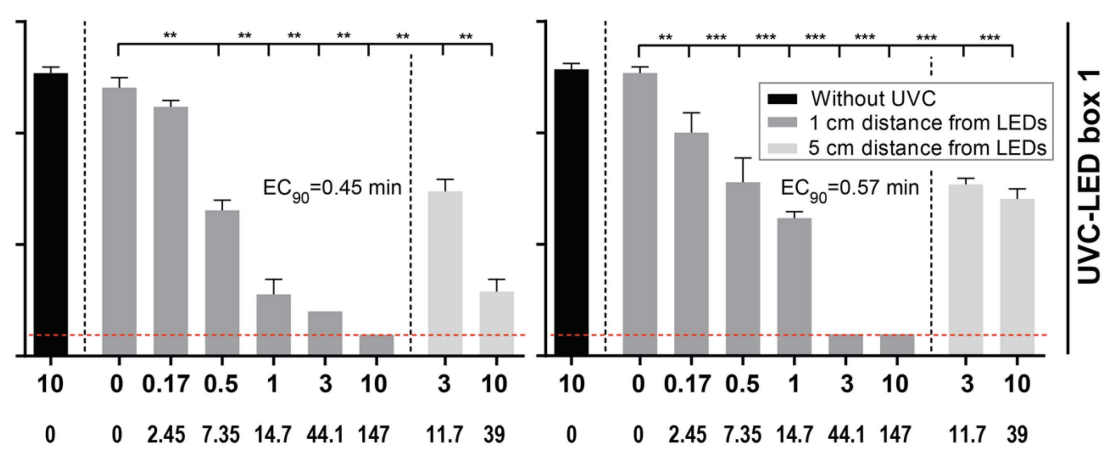

Metal

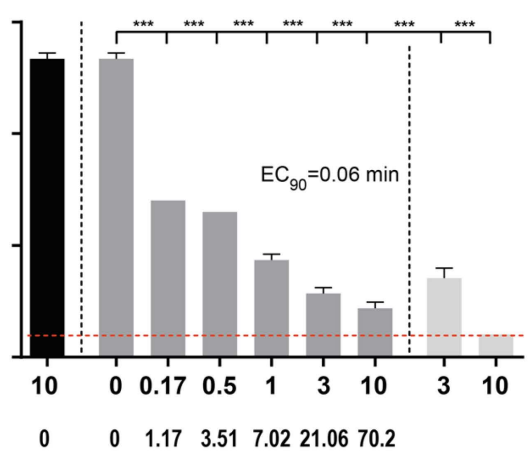

Figure 3. Disinfection of severe acute respiratory syndrome coronavirus 2 (SARS-CoV-2)-contaminated objects by two distinct UVC-LED boxes. Glass, metal, and plastic samples were contaminated with SARS-CoV-2 at a final concentration of $4.5 \times 10^{6} \mathrm{TCID}_{50} / \mathrm{mL}$ for UVC-LED box 1 and $1.8 \times 10^{6} \mathrm{TCID}_{50} / \mathrm{mL}$ for UVC-LED box 2 in a cell culture medium mixed with defined organic matrix, thereby mimicking the viral contamination on the surfaces of personal belongings such as smartphones, keys, coins, or credit cards. The samples were exposed to LED-UVC light for $0 \mathrm{~s}, 10 \mathrm{~s}, 30 \mathrm{~s}, 1 \mathrm{~min}, 3 \mathrm{~min}$, and $10 \mathrm{~min}$ at different distances from UVC-LEDs inside the UVC-LED boxes. Experiments were conducted in triplicates. (a) In UVC-LED box 1, samples were irradiated at distance of 1 and $5 \mathrm{~cm}$ from the UVC-LEDs. (b) In UVC-LED box 2 , samples were irradiated at 1 and $4 \mathrm{~cm}$ from the UVC-LEDs. Light doses at $4 \mathrm{~cm}$ distance cannot be shown, as an irradiance measurement of the LEDs at that distance would have required drilling a hole into the bottom of the box, which was not possible without damaging the box. The limit of detection of the assay was at $159 \mathrm{TCID}_{50} / \mathrm{mL}$ (indicated by the red dotted line). Data are displayed as mean \pm SD. ${ }^{* *} p<0.01 ; * * *<0.001$; and ${ }^{* * * *} p<0.0001$. TCID $_{50}=$ tissue culture infectious dose, $50 \% ; \mathrm{EC}_{90}=90 \%$ effective concentration.

\section{Discussion}

SARS-CoV-2 is transmitted through direct contact with infected individuals, by viruscontaining aerosols and potentially via contact with virus-contaminated surfaces [3]. In the present study, we investigated the performance of UVC-LED sterilization boxes on the inactivation of SARS-COV-2 on surfaces such as glass, metal, and plastics that are typically found on personal items like smart phones, credit cards, or keys. We demonstrated that UVC-LED boxes can effectively inactivate SARS-CoV-2 on glass, metal, and plastic. Independent of the used UVC-LED box and the materials, SARS-CoV-2 could be almost completely inactivated after 3 min exposure (UVC-LED box $1: 1 \mathrm{~cm}: 44.1 \mathrm{~mJ} / \mathrm{cm}^{2}, 5 \mathrm{~cm}$ : $11.7 \mathrm{~mJ} / \mathrm{cm}^{2}$; UVC-LED box 2: $1 \mathrm{~cm}: 21.06 \mathrm{~mJ} / \mathrm{cm}^{2}$ ), which represents the standard exposure time provided by the UVC-LED boxes. Even $10 \mathrm{~s}$ of exposure strongly reduced viral loads on the contaminated surfaces.

The findings are in line with other studies that report susceptibility of coronaviruses, including SARS-CoV-1 and SARS-CoV-2 to UVC irradiation $[7,10]$. To almost completely inactivate high viral loads of SARS-CoV-1, a UVC-dose of $1446 \mathrm{~mJ} / \mathrm{cm}^{2}$ was necessary [10]. 
High viral loads of SARS-CoV-2 could be completely inactivated by a UVC dose of $1048 \mathrm{~mJ} / \mathrm{cm}^{2}$ [7]. The results of the present study show that the distance of the inoculated materials from the LEDs and thus the emitted light intensity is a decisive factor for achieving the complete inactivation of SARS-CoV-2. Accordingly, it has recently been reported that distance and angle of UVC light source in closed box systems are important factors for irradiance over respirator surfaces [11]. UVC-LED box 1 and 2 showed a similar reduction of viral load for the materials glass and plastic. At a distance of $5 \mathrm{~cm}$ from the LED of UVC-LED box 1 , although the viral load was reduced by $91.92 \pm 1.85 \%\left(1.1 \pm 0.08 \log _{10}\right)$ on glass, $98.52 \pm 0.42 \%\left(1.83 \pm 0.09 \log _{10}\right)$ on metal and $92.56 \pm 1.7 \%\left(1.13 \pm 0.8 \log _{10}\right)$ on plastic, the emitted light intensity $\left(65 \mu \mathrm{W} / \mathrm{cm}^{2}\right)$ was not sufficient to completely inactivate the virus after $10 \mathrm{~min}$ exposure. The mirror at the bottom of UVC-LED box 2 may have contributed to facilitating the inactivation of the virus. Van Doremalen et al. [4] indicated that a SARS-CoV-2 stock with a viral concentration of $10^{5} \mathrm{TCID}_{50} / \mathrm{mL}$ corresponds to cycle threshold values between 20 and 22, which is similar to the thresholds of samples from the upper and lower respiratory tracts of infected individuals. In this study, SARS-CoV-2 stocks with even higher viral concentrations of about $10^{6} \mathrm{TCID}_{50} / \mathrm{mL}$ were used for the inoculation of the materials.

Overall, both UVC-LED boxes were highly effective in inactivating the high-titer viral stocks of SARS-CoV-2. However, in this study, we did not test the stability of the emission of the UVC-LED boxes. Therefore, no statement can be made as to whether the emission of the devices is stable during prolonged use over weeks or months.

The encouraging results of the study make the UVC-LED boxes an affordable option for the public to disinfect a variety of items, including phones, watches, headphones, masks, and makeup utensils, as long as the item size fits the device. Because SARS-CoV-2 can also be detected on different surfaces in hospital environment [12,13], UVC-LED boxes might also be an effective tool for environmental decontamination in hospitals.

Author Contributions: Conceptualization, A.K.; methodology, A.K., M.B., T.L.M. and E.S.; investigation, M.B., L.S., M.O. and L.v.d.S.; resources, U.D. and O.W.; data analysis, M.B. and M.A.; writing—original draft preparation, M.B. and A.K.; writing—review and editing, M.B., A.K., T.L.M., E.S. and U.D.; visualization, M.B. and M.A.; supervision, A.K. All authors have read and agreed to the published version of the manuscript.

Funding: This study was supported by the Stiftung Universitätsmedizin Essen (awarded to A. Krawczyk) and the Rudolf Ackermann Foundation (awarded to O. Witzke).

Institutional Review Board Statement: Not applicable.

Informed Consent Statement: Not applicable.

Data Availability Statement: The data presented in this study are available on request from the corresponding author.

Acknowledgments: We thank Oliver Lischtschenko from Ocean Optics B.V. for providing us with the spectrometer and his technical support.

Conflicts of Interest: The authors declare that the research was conducted in the absence of any commercial or financial relationship that could be construed as a potential conflict of interest.

\section{References}

1. Raoult, D.; Zumla, A.; Locatelli, F.; Ippolito, G.; Kroemer, G. Coronavirus infections: Epidemiological, clinical and immunological features and hypotheses. Cell Stress 2020, 4, 66-75. [CrossRef] [PubMed]

2. Guan, W.J.; Ni, Z.Y.; Hu, Y.; Liang, W.H.; Ou, C.Q.; He, J.X.; Liu, L.; Shan, H.; Lei, C.L.; Hui, D.S.C.; et al. Clinical Characteristics of Coronavirus Disease 2019 in China. N. Engl. J. Med. 2020, 382, 1708-1720. [CrossRef] [PubMed]

3. World Health Organization. Modes of Transmission of Virus Causing COVID-19: Implications for IPC Precaution Recommendations. 2020. Available online: https:/ / www.who.int/news-room/commentaries/detail/modes-of-transmission-of-virus-causi ng-covid-19-implications-for-ipc-precaution-recommendations (accessed on 1 March 2021). 
4. Van Doremalen, N.; Bushmaker, T.; Morris, D.H.; Holbrook, M.G.; Gamble, A.; Williamson, B.N.; Tamin, A.; Harcourt, J.L.; Thornburg, N.J.; Gerber, S.I.; et al. Aerosol and Surface Stability of SARS-CoV-2 as Compared with SARS-CoV-1. N. Engl. J. Med. 2020, 382, 1564-1567. [CrossRef] [PubMed]

5. Menetrez, M.Y.; Foarde, K.K.; Dean, T.R.; Betancourt, D.A. The effectiveness of UV irradiation on vegetative bacteria and fungi surface contamination. Chem. Eng. J. 2010, 157, 443-450. [CrossRef]

6. Norval, M.; El-Ghorr, A.; Garssen, J.; Van Loveren, H. The effects of ultraviolet light irradiation on viral infections. Br. J. Dermatol. 1994, 130, 693-700. [CrossRef] [PubMed]

7. Heilingloh, C.S.; Aufderhorst, U.W.; Schipper, L.; Dittmer, U.; Witzke, O.; Yang, D.; Zheng, X.; Sutter, K.; Trilling, M.; Alt, M.; et al. Susceptibility of SARS-CoV-2 to UV irradiation. Am. J. Infect. Control. 2020, 48, 1273-1275. [CrossRef] [PubMed]

8. Spearman, C. The method of Right and Wrong cases (Constant Stimuli) without Gauss's formulae. Br. J. Psychol. 1908, 2, 227. [CrossRef]

9. Sattar, S.; Ansari, S. The fingerpad protocol to assess hygienic hand antiseptics against viruses. J. Virol. Methods 2002, 103, 171-181. [CrossRef]

10. Darnell, M.E.; Subbarao, K.; Feinstone, S.M.; Taylor, D.R. Inactivation of the coronavirus that induces severe acute respiratory syndrome, SARS-CoV. J. Virol. Methods 2004, 121, 85-91. [CrossRef] [PubMed]

11. Baluja, A.; Arines, J.; Vilanova, R.; Cortiñas, J.; Bao-Varela, C.; Flores-Arias, M.T. UV light dosage distribution over irregular respirator surfaces. Methods and implications for safety. J. Occup. Environ. Hyg. 2020, 17, 390-397. [CrossRef] [PubMed]

12. Ong, S.W.X.; Lee, P.H.; Tan, Y.K.; Ling, L.M.; Ho, B.C.H.; Ng, C.G.; Wang, D.L.; Tan, B.H.; Leo, Y.S.; Ng, O.T.; et al. Environmental contamination in a coronavirus disease 2019 (COVID-19) intensive care unit-What is the risk? Infect. Control Hosp. Epidemiol. 2020, 1-9. [CrossRef]

13. Ye, G.; Lin, H.; Chen, S.; Wang, S.; Zeng, Z.; Wang, W.; Zhang, S.; Rebmann, T.; Li, Y.; Pan, Z.; et al. Environmental contamination of SARS-CoV-2 in healthcare premises. J. Infect. 2020, 81, e1-e5. [CrossRef] [PubMed] 